\section{ENSAIO DA AÇĀO ACARICIDA DE PERMETHRIN SOBRE DERMANYSSUS GALLINAE (DE GEER, 1778), EM CONDIÇOES DE CAMPO}

\section{MARIA SHIRLEY PIZOLATO OBA}

Professor Assistente Doutor Instituto de Ciências Biomédicas da USP

ARLETE DELL'PORTO

Professor Assistente Instituto de Ciências Biomédicas da USP

VANDERLEI AMARAL BENEDITO Médico Veterinário

OBA, M.S.P.; DELL'PORTO, A.; BENEDITO, V.A. Ensaio da ação acaricida de Permethrin sobre Dermanyssus gallinae (de Geer, 1778), em condiçðes de campo. Rev.Fac.Med.vet.Zootec.Univ. S.Paulo, 19(1): 35-37, 1982.

RESUMO: Para a avaliação da eficiência acaricida de Permethrin sobre população pura de Dermanyssus gallinae, realizou-se ensaio "in vivo" em granja avícola do Município de Mogi das Cruzes, Estado de São Paulo. Os resultados obtidos demonstraram sua eficiência de $100 \%$ na concentração de $0,05 \%$ de princípio ativo.

UNITERMOS: Dermanyssus gallinae*; Permethrin, aves; Pesticidas*; Acarina, aves*;

\section{INTRODUÇÃO}

O controle de Dermanyssus gallinae (De Geer, 1778), bem como de Ornithonyssus sylviarum (Canestrini e Fanzago, 1977), torna-se necessário quando suas populações nos aviários passam a causar danos. Estes ácaros hematófagos são conhecidos pelos avicultores pelo nome de "piolho vermelho das aves". São comumente encontrados em criações de aves a nivel industrial, bem como, nas de fundo de quintal.

Esses dois ectoparasitas de aves apresentam variaçōes biológicas, pois $\mathbf{D}$. gallinae alimenta-se à noite ou em ambientes escuros. Suas colônias instalam-se nas frinchas das instalações do aviário, sob o cocho de ração e o de água e, quando perturbados, espalham-se rapidamente ao redor do esconderijo.

O. sylviarum é encontrado sobre as aves, nas regióes da cabeça, do ventre e pericloacal, dando às aves um aspecto de sujeira, ocasionado pela presença de ovos do parasita, pele de mudas e de ácaros sobre as penas. Nas altas infestaçôes, são encontrados sobre os ovos das aves e instalações.

SIKES e CHAMBERLAIN 6 (1954), verificaram que o peso médio de uma fêmea ingurgitada de $D$. gallinae é de $0,204 \mathrm{mg}$, ingerindo 2,7 vezes seu peso em sangue. $\mathbf{0}$. sylviarum apresenta um peso médio de $0,041 \mathrm{mg}$ e as fêmeas adultas ingerem 1,6 vezes seu peso em sangue.

o. sylviarum, bem como D. gallinae, são comuns em nossas criações. $\mathbf{O}$. sylviarum foi assinalado no Brasil, pela primeira vez, por FACCINI e MASSARDl (1974), no Estado do Rio de Janeiro e, no Estado de São Paulo, por PEREIRA e cols 5 (1977). Rapidamente dispersou-se, sendo hoje um problema nas áreas de criaçðes avícolas.

A ação patogenica do 0 . sylviarum foi detalhadamen. te estudada por MATHYSSE e cols ${ }^{4}$ (1974), que registraram, em altas infestações, perdas na produção de ovos e carne. Esta patogenia é mais acentuada quando se trata de $\mathbf{D}$. gallinae.

HALL e cols 2 (1978) e KISSAN e FURQUERON3 (1980), verificaram em testes de laboratório, a ação de Permethrin (ECTIBAN - ICI do Brasil S/A.), sobre 0. sylviarum, bem como em populaçðes destes ácaros sobre as aves.

Obtiveram para diluiçōes de 0,5 e $0,125 \%$ de princípio ativo, uma eficiência de $100 \%$, assinalando reinfestações no 77o. dia após o tratamento. Para concentração de 0,0125 e $0,05 \%$, a eficiência acaricida também foi de $100 \%$, com reinfestações no $57 \mathrm{o}$. dia após o tratamento.

\section{MATERLAIS E MÉTODOS}

O presente trabalho foi realizado na Granja Tanabe, localizada no município de Mogi das Cruzes, Estado de São Paulo. Nas instalaçōes de madeira desta Granja foram encontrados D. gallinae em quantidades considerada alta subjetivamente. Entre os galpб̃es nestas condições, foi sorteado um de $66 \mathrm{~m}$ de comprimento, abrigando 2.400 aves (3 em cada gaiola). 
Diluiu-se o produto teste em água, na proporção de 1 : 100 , obtendo-se, assim, emulsăo com $0,05 \%$ de princípio ativo.

Para a aplicação da emulsão, utilizamos um pulverizador (spray) com bicos de jatos em leque de 150 libras de pressão. Primeiro, aspergiu-se as instalações e as aves pelo lado de fora do galpão e em seguida pelo centro do aviário. Foram gastos nesta operação, 130 litros da emulsão.

Para avaliação, colheram-se amostras, com auxnlio de espátulas, das frinchas sob us cochos de água e de raçáo, a espaços de aproximadamente 10 metros. As amostras colhidas (de ácaros, ração, penas e fezes) foram colocadas em frascos devidamente rotulados, sendo transportadas para o laboratório do Departamento de Parasitologia do Instituto de Ciências Biomédicas da Universidade de São Paulo, onde foram examinadas sob lupa.

O esquema de colheita das amostras está sumariado no Quadro 1.

QUADRO 1 - Esquema dos tempos adotados para a colheita das amostras.

\begin{tabular}{c|l|l}
\hline Tempo & Momento da colheita das amostras & No. de amostras \\
\hline $\mathrm{T}_{0}$ & antes do tratamento & 20 \\
$\mathrm{~T}_{1}$ & 24 horas após o tratamento & 20 \\
$\mathrm{~T}_{2}$ & 7 dias após o tratamento & 20 \\
$\mathrm{~T}_{3}$ & 15 dias após o tratamento & 20 \\
$\mathrm{~T}_{4}$ & 20 dias após o tratamento & 20 \\
$\mathrm{~T}_{5}$ & 30 dias após o tratamento & 20 \\
\hline
\end{tabular}

\section{RESULTADOS E DISCUSSÃO}

Das 20 amostras colhidas antes do tratamento, em somente uma não foi encontrada D. gallinae; nas demais estavam presentes ovos, larvas, ninfas (ninfas octopodes; proto e deutoninfas) e adultos.

Nas amostras colhidas 24 horas após o tratamento, quatro eram negativas e 16 continham ácaros vivos.
No 7o. dia após o tratamento, 18 amostras revelaram grande número de ácaros mortos (com aspecto de secos) e duas mostraram-se negativas. No 150. dia após o tratamento, em 19 das 20 amostras, encontraram-se alguns ácaros secos. Tanto na amostragem colhida 20 dias quanto na colhida 1 mês após o tratamento, não encontramos D. gallinae quer vivos quer mortos.

Estes resultados estão sumariados no Quadro 2.

QUADRO 2 - Momento da colheita, número de amostras com D. gallinae vivos, mortos ou ausentes.

\begin{tabular}{c|c|c|c}
\hline $\begin{array}{l}\text { Momento da } \\
\text { colheita }\end{array}$ & $\begin{array}{l}\text { No. de amostras com } \\
\text { D. gallinae vivos }\end{array}$ & $\begin{array}{l}\text { No. de amostras com } \\
\text { D. gallinae mortos }\end{array}$ & $\begin{array}{l}\text { No. de amostras } \\
\text { negativas }\end{array}$ \\
\hline $\mathrm{T}_{0}$ & 19 & - & 1 \\
\hline $\mathrm{T}_{1}$ & 16 & - & 4 \\
\hline $\mathrm{T}_{2}$ & - & 18 & 2 \\
\hline $\mathrm{T}_{3}$ & - & 19 & 1 \\
\hline $\mathrm{T}_{4}$ & - & - & 20 \\
\hline $\mathrm{T}_{5}$ & - & - & 20 \\
\hline
\end{tabular}


Nas condiçðes por nós utilizadas, Permethrin na concentração de $0,05 \%$ de princípio ativo, mostrou eficiência acaricida de $100 \%$ para D. gallinae.

Não foi observada reinfestação até um mês após o tratamento, entretanto, trabalhos complementares, com intuito de detectar o momento da reinfestação (poder residual do produto), para períodos acima de um mês seriam desejáveis.
OBA, M.S.P.; DELL'PORTO, A.; BENEDITO, V.A. Field assay of the acaricide activity of Permethrin on Dermanyssus gallinae (De Geer, 1778), Rev.Fac.Med.vet.Zootec.Univ.S.Paulo, 19(1): $35-37,1982$.

SUMMARY: The acaricide efficiency of Permethrin was studied "in vivo" on a pure population of Dermanyssus gallinae in a poultry farm located at Mogi das Cruzes, State of São Paulo. The results showed that Permethrin in a concentration of $0,05 \%$ of the active base had an efficiency of $100 \%$.

UNITERMOS: Dermanyssus gallinae*; Acarina, poultry*; Pesticides, Permethrin*

\section{REFERENCIAS BIBLIOGRÄFICAS}

1 - FACCINI, J.L.H. \& MASSARD, C.L. Nota sobre a ocorrência de Ornithonyssus sylviarum (Canestrini e Fanzago, 1877) (Mesostigmata; Macronyssidae) em Gallus gallus domesticus (L.) no Brasil. Arq.Univ.Fed.Rural R.Juneiro, 4(1):30-40, 1974.

2 - HALL, R.D.; TOWNSEDAD, L.H.; TURNER, E.C. Laboratory and field tests to compare effectiveness of organophosphorus, carbamate, and sinthetic pyrethroid acaricides against northern fowl mites. J.Econ.Ent., 71:315-8, 1978.

3 - KISSAN, J.B. \& FURQUERON, T.C. Comparative efficacy of Ectiban (Permethrin) EC and dust formulations versus Standard commercial sprays for control of northern fowl mite on caged poultry. South Carolina, Department of Entomology and Economic Zoology, Clemson University, 1980. (Unpublished)
4 - MATHYSSE, J.G.; JONES, C.J.; PURNASIRI, A. Development of northern fowl mites. Populations on chickens, effects on the host and immunology. Search Agric.Ent., 4(9):1-38, 1974.

5 - PEREIRA, M.C.; OBA, M.S.P.; SCHUMACKER, T.T. S. Ormithonyssus sylviarum (Canestrini e Fanzago, 1877) (Mesostigmata: Macronyssidae) em Gallus gallus domesticus (L.) no Estado de São Paulo, Brasil. Rev.Fac.Med.vet.Zootec.Univ.S. Paulo, 14(2):243-51, 1977.

6 - SIKES, R. \& CHAMBERLAIN, R.W. Laboratory observations on three species of bird mites. J.Parasit., 40:691-7, 1954 .

Recebido para publicação em: 02-03-82. Aprovado para publicação em: $01-09.82$. 